\title{
Peripheral Serotonin: a New Player in Systemic Energy Homeostasis
}

\author{
Jun Namkung ${ }^{1}$, Hail Kim ${ }^{1, *}$, and Sangkyu Park ${ }^{2 *}$
}

\begin{abstract}
Whole body energy balance is achieved through the coordinated regulation of energy intake and energy expenditure in various tissues including liver, muscle and adipose tissues. A positive energy imbalance by excessive energy intake or insufficient energy expenditure results in obesity and related metabolic diseases. Although there have been many obesity treatment trials aimed at the reduction of energy intake, these strategies have achieved only limited success because of their associated adverse effects. An ancient neurotransmitter, serotonin is among those traditional pharmacological targets for anti-obesity treatment because it exhibits strong anorectic effect in the brain. However, recent studies suggest the new functions of peripheral serotonin in energy homeostasis ranging from the endocrine regulation by gut-derived serotonin to the autocrine/paracrine regulation by adipocyte-derived serotonin. Here, we discuss the role of serotonin in the regulation of energy homeostasis and introduce peripheral serotonin as a possible target for anti-obesity treatment.
\end{abstract}

\section{INTRODUCTION}

Serotonin (5-hydroxytryptamine, 5-HT) is a neurotransmitter that is synthesized from the essential amino acid tryptophan by the sequential actions of tryptophan hydroxylase (TPH) and aromatic amino acid decarboxylase. Once serotonin is released, it exerts its biological action by binding to serotonin receptor (HTR). Its action is then terminated by uptake into cells through the serotonin transporter (SERT, Slc6a4) (Wade et al., 1996). Thus, serotonin is commonly thought to act locally in neural and paracrine circuits, and its functions vary depending on the tissues (Gershon and Tack, 2007).

The hydroxylation of tryptophan is the rate-limiting step in serotonin synthesis. Serotonin production is regulated by the activity of TPH and the availability of tryptophan. There are two

\footnotetext{
${ }^{1}$ Graduate School of Medical Science and Engineering, Korea Advanced Institute of Science and Technology, Daejeon 34141, Korea, ${ }^{2}$ Department of Biochemistry, College of Medicine, Catholic Kwandong University, Gangwon 25601, Korea

*Correspondence: 49park@cku.ac.kr (SP); hailkim@kaist.edu (HK)
}

Received 30 September, 2015; revised 26 November, 2015; accepted 26 November, 2015; published online 1 December, 2015

Keywords: adipose tissue, energy homeostasis, obesity, tryptophan hydroxylase, serotonin isoforms of $\mathrm{TPH}$; $\mathrm{TPH} 1$ is primarily expressed in peripheral tissues, whereas TPH2 is expressed in the central nervous system (CNS) (Walther and Bader, 2003; Zhang et al., 2004). Because serotonin cannot cross the blood-brain barrier, the central and peripheral serotonergic systems are functionally separated. In the CNS, serotonin is produced in the raphe nuclei of the brainstem and hypothalamus. By functioning as a neurotransmitter in CNS, serotonin regulates mood (Merens et al., 2007; Young and Leyton, 2002), sleep-wake behavior (Monti, 2011) and food intake (Lam et al., 2010). In the periphery, serotonin is mainly produced in the gut and pineal gland. Approximately $90 \%$ of serotonin in the body is produced by $\mathrm{TPH} 1$ in enterochromaffin cells in the gut, where it regulates intestinal motility (Keszthelyi et al., 2009). Gut-derived serotonin (GDS) is stored in platelets and controls hemodynamics upon activation of platelets (Keszthelyi et al., 2009). Serotonin is also present in other peripheral tissues (Gershon and Ross, 1966); it has been shown to play different roles in the mammary gland (Matsuda et al., 2004), liver (Lesurtel et al., 2006), and bone (Yadav et al., 2008) as well as in pancreatic $\beta$-cells (Kim et al., 2010; 2015; Ohara-Imaizumi et al., 2013).

Body energy homeostasis is a primitive and fundamental biological function that is regulated through complex physiological processes. As an ancient neurotransmitter that is conserved throughout the animal phyla, serotonin is a good candidate to play a fundamental role in the regulation of energy homeostasis At least 14 HTRs, grouped into 7 families according to the signaling mechanisms, are widely expressed in mammalian tissues. This diversity of HTRs can provide diverse effects of serotonin on target cells (Hannon and Hoyer, 2008). Indeed, the functions of serotonin in energy homeostasis range from central control of food intake to direct regulation of adipose tissue activity in the periphery. In this review, we discuss the functional role of serotonin in systemic energy homeostasis.

\section{CENTRAL REGULATION OF ENERGY HOMEOSTASIS BY SEROTONIN}

Central serotonin has been considered a target for anti-obesity treatment since an inverse relationship between central serotonin level and food intake was established. Fenfluramine, which increases serotonin release, is the prototypical agent for serotonergic suppression of feeding (Lam and Heisler, 2007). Inhibiting serotonin synthesis in the brain via intraventricular injection of p-chlorophenylalanine (PCPA), an irreversible TPH inhibitor, induces hyperphagia and weight gain in rats (Breisch et al., 1976). Serotonin reuptake inhibitors, such as sibutramine 
and fluoxetine, and monoamine oxidase inhibitors, such as clorgyline and pargyline, reduce food intake (Feldman, 1988; Heal et al., 1998; Heisler et al., 1997). Thus, central serotonin functions as an anorexigenic neurotransmitter.

Studies using receptor-specific drugs and knock-out (KO) mice have provided insight into the role of specific HTRs in regulating appetite. The involvement of HTR2C and HTR1B was initially suggested by the anorectic effect of $\mathrm{m}$ chlorophenylpiperazine (mCPP) (Kennett and Curzon, 1988). Anorectic effect of fenfluramine was attenuated by HTR2C antagonist (Vickers et al., 1999). HTR2C agonist induced hypophagia (Lam et al., 2008) and improved glucose tolerance and insulin sensitivity in obese mouse model (Zhou et al., 2007). A major contribution of HTR2C to feeding control was confirmed by a study of Htr2c KO mice (Tecott et al., 1995). Htr2c KO mice are hyperphagic and obese, and the anorectic effect of mCPP disappears in Htr2c KO mice (Nonogaki et al., 1998). However, the anorectic effect of leptin is not related to Htr2c KO. In addition, Htr1b KO mice exhibited hyperphagia (Bouwknecht et al., 2001) and a selective HTR1B agonist induced hypophagia in mice (Halford and Blundell, 1996). Recently, lorcaserin ([1R]-8-Chloro-2,3,4,5tetrahydro-1-methyl-1H-3-benzazepine), a selective HTR2C agonist, was approved for obesity treatment (Colman et al., 2012). Lorcaserin decreased body weight without influencing energy expenditure (Martin et al., 2010).

Appetite is regulated by the hypothalamic feeding circuits (Sohn et al., 2013). Briefly, anorexigenic proopiomelanocortin (POMC) neurons release $\alpha$-melanocyte-stimulating hormone $(\alpha-\mathrm{MSH})$, the endogenous ligand of the melanocortin 4 receptor (MC4R), to reduce appetite and food intake. Orexigenic neuropeptide Y/agouti-related peptide (NPY/AgRP) neurons increase appetite and food intake by releasing the endogenous MC4R antagonist AgRP, and they suppress POMC neurons by releasing GABA. Studies of the effects of serotonin on the hypothalamic feeding circuits revealed that serotonin reciprocally activates POMC neurons through HTR2C while inhibiting NPY/AgRP neurons via HTR1B (Heisler et al., 2002). Taken together, central serotonin inhibits food intake by modulating hypothalamic feeding circuits (Fig. 1).

Since TPH2 is responsible for the serotonin production in the brain, Tph2 KO mice were expected to be hyperphagic and obese. Although central serotonin levels were selectively decreased, the body weights of Tph2 KO mice were lower than littermate control (Alenina et al., 2009; Gutknecht et al., 2012; Savelieva et al., 2008). In addition, Htr1b KO mice did not develop obesity, despite having hyperphagia (Bouwknecht et al., 2001). These findings suggest that central serotonin may upregulate energy expenditure in the body. Indeed, intra-ventricular injection of serotonin increases resting oxygen consumption without obvious behavioral effects (Le Feuvre et al., 1991). The injection of serotonin into the paraventricular nucleus and ventromedial nucleus of the hypothalamus increases sympathetic tone, resulting in the upregulation of the activity of brown adipose tissue (BAT) (Sakaguchi and Bray, 1989). Fenfluramine also increases sympathetic tone and activates BAT that is reversed by BAT sympathectomy (Arase et al., 1988; Rothwell and Stock, 1987). Taken together, these findings indicate that central serotonin decreases energy intake by reducing appetite and increases energy expenditure by activating BAT through the sympathetic nervous system.

\section{PERIPHERAL REGULATION OF ENERGY HOMEOSTASIS BY SEROTONIN}

In contrast to the anorectic effect of central serotonin, several lines of evidences suggest different functions of serotonin in the periphery. Slc6a4 (SERT) KO mice were expected to be slim due to the increased serotonin activity in the brain; however, they exhibited an obese phenotype (Murphy and Lesch, 2008). Body weight is reduced in Tph1 and Tph2 double $\mathrm{KO}$ mice as well as in Tph1 KO mice (Alenina et al., 2009; Gutknecht et al., 2012; Savelieva et al., 2008). In addition, the enhancement of serotonin activity using a selective SERT inhibitor (SSRI) is associated with transient weight loss (Serretti and Mandelli, 2010). These discordant results suggest that peripheral serotonin and central serotonin play opposite roles in the regulation of energy homeostasis.

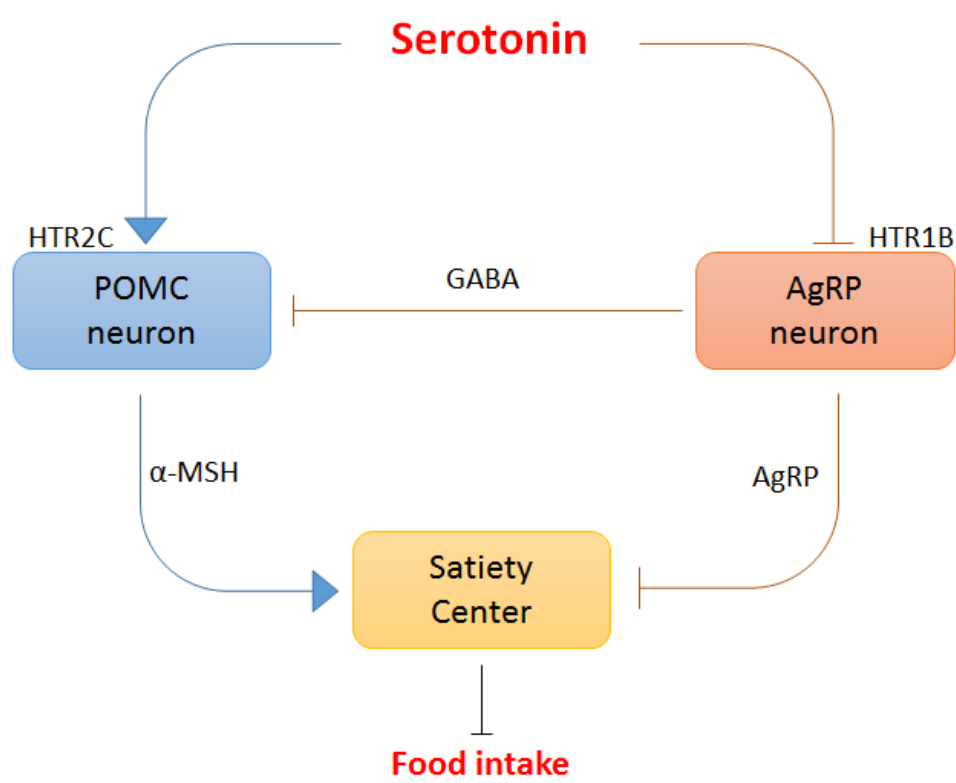

Fig. 1. Appetite is regulated by central serotonin Serotonin acts via HTR1B and HTR2C on downstream melanocortin pathways to suppress appetite in the brain. Serotonin suppresses the production and release of AgRP, an endogenous melanocortin receptor antagonist, through HTR1B and increases the production and release of $\alpha-\mathrm{MSH}$, an endogenous melanocortin receptor agonist, through HTR2C. Overall, central serotonin suppresses food intake. 
Peripheral serotonin is produced in the gut and stored in platelets. There is also a small amount of free serotonin in plasma. The level of serotonin in the blood is determined by the production of serotonin from enterochromaffin cells in the gut. Several studies have reported increased serotonin production and blood serotonin levels in various animal models of obesity and diabetes. Kim et al. (2011) reported that the serum serotonin level was elevated in C57BL/6 mice fed a high fat diet (HFD) compared to mice fed a low fat diet (LFD). Bertrand et al. reported that rats fed a Western diet showed increased expression of Tph1 and increased serotonin secretion from the gut (Bertrand et al., 2011). Haub et al. also reported that duodenal serotonin content was increased in ob/ob mice, a mouse model of obesity (Haub et al., 2011). In contrast, Sumara et al. (2012) documented that fasting induced serotonin production in the gut, modestly increasing the plasma serotonin level. Difficulties in measuring blood serotonin levels are responsible for these discrepant blood serotonin levels (Brand and Anderson, 2011). Although Kim et al. (2011) identified serotonin as the most highly upregulated metabolite in the serum of mice fed an HFD, this data needs to be interpreted carefully. They used an LFD as a control instead of a standard chow diet. An LFD contains more carbohydrate than an HFD. This difference can substantially change the availability of tryptophan and affect serotonin production in the periphery and brain. Bertrand et al. (2011) and Haub et al. (2011) reported increased serotonin production in the gut, but they did not measure blood serotonin levels directly. Sumara et al. (2012) reported a modest increase in plasma serotonin levels, which reached $24 \mu \mathrm{M}$ after $48 \mathrm{~h}$ of fasting. However, $24 \mu \mathrm{M}$ plasma serotonin is a much higher concentration than that usually observed. Earlier reports of serotonin concentration in platelet-poor plasma have ranged from 0.6 to $179 \mathrm{nM}$, with a mean of $31.6 \mathrm{nM}$ and a median of $14.8 \mathrm{nM}$ (Brand and Anderson, 2011). Thus, whether feeding or fasting changes blood serotonin concentrations remains an open question.
Since the 1960s, the biological functions of peripheral serotonin in the regulation of energy homeostasis have been extensively studied using chemical agonists and antagonists. However, most of data are controversial because of off-target effects. Recently, tissue-specific gene $\mathrm{KO}$ technology has allowed us to dissect the complex functions of HTRs in different tissues. In conjunction with recent studies using tissue-specific gene $\mathrm{KO}$ of serotonergic systems, reinterpreting the data that have been published over the last several decades provides better understanding on the functions of peripheral serotonin in the regulation of energy metabolism.

In the liver, hepatocytes do not produce serotonin. It is released from platelets upon activation and induces hepatic regeneration through HTR2B (Lesurtel et al., 2006). Recently, using gut-specific Tph1 KO mice, Sumara et al. provided clear insight into the important role of GDS in the liver (Sumara et al., 2012). The gut-specific Tph1 KO mice showed improved glucose disposal and reduced hepatic gluconeogenesis, and these effects were diminished by the administration of serotonin. Liver-specific Htr2b KO mice exhibited a similar phenotype (Sumara et al., 2012), indicating that GDS regulates hepatic glucose metabolism through HTR2B. Similar data have indicated that in fasted mice, plasma glucose concentrations are elevated after the injection of serotonin (Watanabe et al., 2010). In contrast to the increased hepatic glucose production that is triggered by serotonin, plasma triglyceride, cholesterol, and nonesterified fatty acid concentrations are decreased after the injection of serotonin (Watanabe et al., 2010). Portal infusion of serotonin also increases hepatic glucose uptake (Moore et al., 2004). These data suggest that serotonin may induce lipogenesis or triacylglycerol synthesis in the liver and/or white adipose tissue (WAT). Indeed, Haub et al. indirectly showed that serotonin increases the fat content in the liver (Haub et al., 2011). Duodenal serotonin content was increased in ob/ob mice, and HTR3 antagonist treatment reduced the elevated serotonin levels and increased SERT in the duodenum. In these mice,

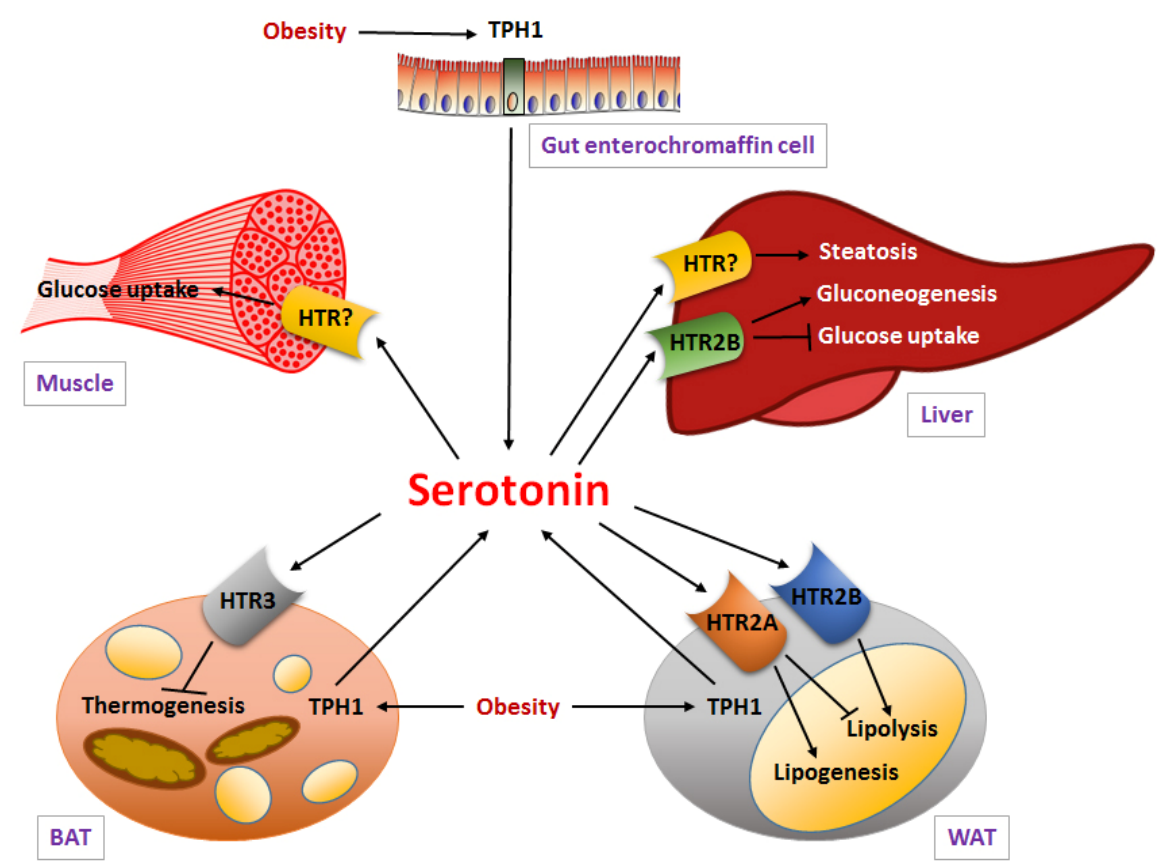

Fig. 2. Energy homeostasis is regulated by peripheral serotonin. TPH1 expression and the production of serotonin in the periphery are increased by an HFD. Adipocyte-derived serotonin may increase energy storage and adipogenesis in WAT through HTR2A and inhibit adaptive thermogenesis in BAT through HTR3. Gutderived serotonin promotes gluconeogenesis and suppresses hepatic glucose uptake through HTR2B, indicating that GDS regulates hepatic glucose metabolism. 
treatment with an HTR3 antagonist also reduced fat content, inflammation, and necrosis in the liver (Haub et al., 2011). Thus, GDS seems to induce hepatic steatosis.

Although S/c6a4 KO mice are obese and the body weights of Tph1 KO mice are reduced (Alenina et al., 2009; Gutknecht et al., 2012; Murphy and Lesch, 2008; Savelieva et al., 2008), the body weights of gut-specific Tph1 KO mice are comparable to those of wild type control mice (Sumara et al., 2012). Furthermore, GDS-induced lipolysis through HTR2B was confirmed in gut-specific Tph1 KO mice and fat-specific Htr2b KO mice (Sumara et al., 2012). These discordant data suggest that serotonin other than GDS may play a different role in the regulation of systemic energy homeostasis. Because lipid accumulation in adipose tissue is a key feature of obesity, adipose tissue is the most likely candidate. Recently, two independent studies have highlighted the role of adipocyte-derived serotonin in energy storage in WAT and in energy expenditure in BAT (Crane et al., 2015; Oh et al., 2015). In a diet-induced obesity mouse model, Tph1 expression and tissue serotonin concentrations were increased in epididymal and subcutaneous WAT (Oh et al., 2015) as well as in BAT (Crane et al., 2015). Crane et al. (2015) showed that Tph1 KO mice were protected from obesity and related metabolic dysfunctions. Tph1 KO mice gained significantly less weight and had lower adiposity and less hepatic lipid accumulation when fed an HFD. Glycemic control was improved in Tph1 $\mathrm{KO}$ mice as well, although glucose uptake was similar in the muscle, liver and heart, indicating the contribution of BAT to the increased basal metabolic rate (Crane et al., 2015). Indeed, Tph1 KO mice showed similar food intake, but their energy expenditure was enhanced. BAT activity increased in a UCP1-dependent manner in Tph1 KO mice. The obesogenic action of peripheral serotonin was confirmed again using a peripheral TPH inhibitor LP-533401 (Crane et al., 2015).

Oh et al. (2015) independently demonstrated similar functions of peripheral serotonin using the systemic TPH inhibitor PCPA and the peripheral TPH inhibitor LP-533401. Intraperitoneal injection of PCPA resulted in decreased weight gain and lower adiposity after an HFD, although intraventricular injection of PCPA reduced serotonin production in the brain and induced hyperphagia and obesity (Breisch et al., 1976; Oh et al., 2015). Systemic PCPA injection reduced lipogenesis in WAT and induced beige adipogenesis in inguinal WAT as well as increased BAT activity, thereby decreasing adiposity and improving glucose homeostasis and insulin sensitivity. In particular, both PCPA and LP-533401 induced the expression of UCP1 and DIO2 in BAT and inguinal WAT (Oh et al., 2015). Furthermore, a cell-autonomous effect of serotonin in adipose tissue has been shown in adipocyte-specific Tph1 KO mice (Oh et al., 2015). In BAT, $\beta$-adrenergic signaling turns on the thermogenic gene program through an intracellular increase in cyclic AMP (CAMP). CAMP then activates protein kinase $A(P K A)$ and downstream targets of PKA, thereby inducing UCP1 expression (Collins et al., 2010). Adipocyte-specific Tph1 KO induced UCP1 and DIO2 expression in BAT (Oh et al., 2015). Basal cAMP levels and PKA activity were higher in the BAT of the adipocyte-specific Tph1 $\mathrm{KO}$ mice, and serotonin attenuated the isoproterenol-mediated increase in intracellular cAMP in BAT (Crane et al., 2015). In addition, HFD robustly induced beige adipogenesis in inguinal WAT of the adipocyte-specific Tph1 KO mice (Oh et al., 2015). Taken together, these recent studies suggest that serotonin negatively regulates the sensitivity of adipose tissues to $\beta$-adrenergic stimulation.

HTR2A and HTR3 have been identified as receptors mediating the obesogenic effects of serotonin in adipose tissues. Dietinduced thermogenesis was robustly increased in the BAT of
Htr3a KO mice (Oh et al., 2015). In immortalized brown adipocytes, HTR3 antagonist activated the PKA pathway by increasing CAMP production and increased mitochondrial respiration (Oh et al., 2015). Thus, Htr3a KO mice were resistant to HFDinduced obesity and showed the improved insulin sensitivity upon an HFD. In contrast to Tph1 KO mice, Htr3a KO mice maintained WAT mass and did not show histological differences compared with littermate control mice, suggesting that another HTR plays a different role in WAT (Oh et al., 2015). In vitro experiments using 3T3-L1 adipocytes have provided a hint of the role of serotonin in adipogenesis (Kinoshita et al., 2010; Oh et al., 2015). Serotonin is produced in mature adipocytes and TPH1 expression is required for the differentiation of 3T3-L1 preadipocytes (Kinoshita et al., 2010). Treatment with a TPH inhibitor or disruption of Tph1 gene in 3T3-L1 preadipocytes resulted in reduced adipogenesis (Kinoshita et al., 2010), and serotonin increased lipid accumulation in human and mouse fat cells (Gres et al., 2013). HTR2A expression increased in the hypertrophied 3T3-L1 adipocytes and WAT of $d b / d b$ mice, and HTR2A activation reduced adiponectin expression in hypertrophied 3T3-L1 adipocytes (Uchida-Kitajima et al., 2008). HTR2A antagonist inhibited adipogenesis (Kinoshita et al., 2010), and HTR2A agonist increased lipid accumulation (Oh et al., 2015). HTR2A antagonists increased circulating adiponectin levels in diabetic patients (Nomura et al., 2005; Yamakawa et al., 2003). Thus, serotonin increases energy storage in WAT through HTR2A and inhibits energy expenditure in BAT through HTR3.

\section{CONCLUSION}

Based on the newly identified roles of peripheral serotonin in energy homeostasis, serotonin can be considered as an energy-saving hormone. Modulating the peripheral serotonergic system may be a good strategy for anti-obesity treatment because it can decrease obesity and increase insulin sensitivity. In general, receptor-specific activation or inhibition is thought to be a better strategy for drug development. However, serotonin plays different roles in different tissues by acting through different receptors. Thus, inhibition of serotonin synthesis in adipose tissue is a potentially beneficial strategy for anti-obesity treatment. This strategy increases insulin sensitivity by simultaneously decreasing lipogenesis and increasing adaptive thermogenesis.

There are still several questions remained to be solved. Mitochondrial biogenesis was enhanced in BAT by Htr3 or Tph1 KO but the mechanism how serotonin regulates mitochondrial biogenesis and function is largely unknown. How the inhibition of serotonin synthesis induces beige adipogenesis and which HTR is responsible for the beige adipogenesis are also unknown, as is the mechanism that underlies GDS-mediated regulation of hepatic steatosis. It is also of interest to know how serotonin plays opposite functions in WAT by acting through HTR2A and HTR2B, which increases lipogenesis and lipolysis, respectively.

The evidences in support of serotonin as a metabolic regulator in the development of obesity are increasing. Nonetheless, the majority of the data are derived from animal studies, and the clinical relevance of serotonin in humans remains undetermined. More accurate information regarding blood serotonin levels in different clinical settings also needs to be obtained.

\section{ACKNOWLEDGMENTS}

This research was supported by the Bio \& Medical Technology Development Program of the National Research Foundation of Korea (NRF), which is funded by the Korean government, 
MSIP (NRF-2014M3A9D5A01073546 to H.K.), and by the Basic Science Research Program of the NRF, which is funded by the Ministry of Education (NRF-2015R1D1A3A03015699 to S.P.)

\section{REFERENCES}

Alenina, N., Kikic, D., Todiras, M., Mosienko, V., Qadri, F., Plehm, R., Boye, P., Vilianovitch, L., Sohr, R., Tenner, K., et al. (2009). Growth retardation and altered autonomic control in mice lacking brain serotonin. Proc. Natl. Acad. Sci. USA 106, 10332-10337.

Arase, K., Sakaguchi, T., and Bray, G.A. (1988). Effect of fenfluramine on sympathetic firing rate. Pharmacol. Biochem. Behav. 29, 675-680.

Bertrand, R.L., Senadheera, S., Markus, I., Liu, L., Howitt, L., Chen, H., Murphy, T.V., Sandow, S.L., and Bertrand, P.P. (2011). A Western diet increases serotonin availability in rat small intestine. Endocrinology 152, 36-47.

Bouwknecht, J.A., van der Gugten, J., Hijzen, T.H., Maes, R.A., Hen, R., and Olivier, B. (2001). Male and female 5-HT(1B) receptor knockout mice have higher body weights than wildtypes. Physiol. Behav. 74, 507-516.

Brand, T., and Anderson, G.M. (2011). The measurement of plateletpoor plasma serotonin: a systematic review of prior reports and recommendations for improved analysis. Clin. Chem. 57, 13761386.

Breisch, S.T., Zemlan, F.P., and Hoebel, B.G. (1976). Hyperphagia and obesity following serotonin depletion by intraventricular pchlorophenylalanine. Science 192, 382-385.

Collins, S., Yehuda-Shnaidman, E., and Wang, H. (2010). Positive and negative control of Ucp1 gene transcription and the role of [beta]-adrenergic signaling networks. Int. J. Obes. 34, S28-S33.

Colman, E., Golden, J., Roberts, M., Egan, A., Weaver, J., and Rosebraugh, C. (2012). The FDA's assessment of two drugs for chronic weight management. N Eng. J. Med. 367, 1577-1579.

Crane, J.D., Palanivel, R., Mottillo, E.P., Bujak, A.L., Wang, H., Ford, R.J., Collins, A., Blumer, R.M., Fullerton, M.D., Yabut, J.M., et al. (2015). Inhibiting peripheral serotonin synthesis reduces obesity and metabolic dysfunction by promoting brown adipose tissue thermogenesis. Nat. Med. 21, 166-172.

Feldman, J.M. (1988). Effect of the monoamine oxidase inhibitors clorgyline and pargyline on the hyperphagia of obese mice. Behav. Brain Res. 29, 147-158.

Gershon, M.D., and Ross, L.L. (1966). Location of sites of 5hydroxytryptamine storage and metabolism by radioautography. J. Physiol. 186, 477-492.

Gershon, M.D., and Tack, J. (2007). The serotonin signaling system: from basic understanding to drug development for functional GI disorders. Gastroenterology 132, 397-414.

Gres, S., Canteiro, S., Mercader, J., and Carpene, C. (2013). Oxidation of high doses of serotonin favors lipid accumulation in mouse and human fat cells. Mol. Nutr. Food Res. 57, 1089-1099.

Gutknecht, L., Araragi, N., Merker, S., Waider, J., Sommerlandt, F.M., Mlinar, B., Baccini, G., Mayer, U., Proft, F., Hamon, M., et al. (2012). Impacts of brain serotonin deficiency following Tph2 inactivation on development and raphe neuron serotonergic specification. PLoS One 7, e43157.

Halford, J.C.G., and Blundell, J.E. (1996). The 5-HT1B receptor agonist CP-94,253 reduces food intake and preserves the behavioural satiety sequence. Physiol. Behav. 60, 933-939.

Hannon, J., and Hoyer, D. (2008). Molecular biology of 5-HT receptors. Behav. Brain Res. 195, 198-213.

Haub, S., Ritze, Y., Ladel, I., Saum, K., Hubert, A., Spruss, A., Trautwein, C., and Bischoff, S.C. (2011). Serotonin receptor type 3 antagonists improve obesity-associated fatty liver disease in mice. J. Pharmacol. Exp. Ther. 339, 790-798

Heal, D.J., Aspley, S., Prow, M.R., Jackson, H.C., Martin, K.F., and Cheetham, S.C. (1998). Sibutramine: a novel anti-obesity drug. A review of the pharmacological evidence to differentiate it from d-amphetamine and d-fenfluramine. Int. J. Obes. Relat. Metab. Disord. 22 Suppl 1, S18-28; discussion S29.

Heisler, L.K., Kanarek, R.B., and Gerstein, A. (1997). Fluoxetine decreases fat and protein intakes but not carbohydrate intake in male rats. Pharmacol. Biochem. Behav. 58, 767-773.

Heisler, L.K., Cowley, M.A., Tecott, L.H., Fan, W., Low, M.J., Smart,
J.L., Rubinstein, M., Tatro, J.B., Marcus, J.N., Holstege, H., et al. (2002). Activation of central melanocortin pathways by fenfluramine. Science 297, 609-611.

Kennett, G.A., and Curzon, G. (1988). Evidence that hypophagia induced by $\mathrm{mCPP}$ and TFMPP requires $5-\mathrm{HT} 1 \mathrm{C}$ and $5-\mathrm{HT} 1 \mathrm{~B}$ receptors; hypophagia induced by RU 24969 only requires 5HT1B receptors. Psychopharmacology (Berl) 96, 93-100.

Keszthelyi, D., Troost, F.J., and Masclee, A.A.M. (2009). Understanding the role of tryptophan and serotonin metabolism in gastrointestinal function. Neurogastroenterol. Motil. 21, 12391249.

Kim, H., Toyofuku, Y., Lynn, F.C., Chak, E., Uchida, T., Mizukami, H., Fujitani, Y., Kawamori, R., Miyatsuka, T., Kosaka, Y., et al. (2010) Serotonin regulates pancreatic beta cell mass during pregnancy. Nat. Med. 16, 804-808.

Kim, H.J., Kim, J.H., Noh, S., Hur, H.J., Sung, M.J., Hwang, J.T., Park, J.H., Yang, H.J., Kim, M.S., Kwon, D.Y., et al. (2011) Metabolomic analysis of livers and serum from high-fat diet induced obese mice. J. Proteome Res. 10, 722-731.

Kim, K., Oh, C.M., Ohara-Imaizumi, M., Park, S., Namkung, J., Yadav, V.K., Tamarina, N.A., Roe, M.W., Philipson, L.H. Karsenty, G., et al. (2015). Functional role of serotonin in insulin secretion in a diet-induced insulin-resistant state. Endocrinology $156,444-452$.

Kinoshita, M., Ono, K., Horie, T., Nagao, K., Nishi, H., Kuwabara, Y. Takanabe-Mori, R., Hasegawa, K., Kita, T., and Kimura, T. (2010). Regulation of adipocyte differentiation by activation of serotonin (5-HT) receptors 5-HT2AR and 5-HT2CR and involvement of microRNA-448-mediated repression of KLF5. Mol. Endocrinol. 24, 1978-1987.

Lam, D.D., and Heisler, L.K. (2007). Serotonin and energy balance: molecular mechanisms and implications for type 2 diabetes. Exp. Rev. Mol. Med. 9, 1-24.

Lam, D.D., Przydzial, M.J., Ridley, S.H., Yeo, G.S.H., Rochford, J.J., O'Rahilly, S., and Heisler, L.K. (2008). Serotonin 5-HT2C receptor agonist rromotes hypophagia via downstream activation of melanocortin 4 receptors. Endocrinology 149, 13231328.

Lam, D.D., Garfield, A.S., Marston, O.J., Shaw, J., and Heisler, L.K (2010). Brain serotonin system in the coordination of food intake and body weight. Pharmacol. Biochem. Behav. 97, 84-91.

Le Feuvre, R.A., Aisenthal, L., and Rothwell, N.J. (1991). Involvement of corticotrophin releasing factor (CRF) in the thermogenic and anorexic actions of serotonin (5-HT) and related compounds. Brain Res. 555, 245-250.

Lesurtel, M., Graf, R., Aleil, B., Walther, D.J., Tian, Y., Jochum, W., Gachet, C., Bader, M., and Clavien, P.A. (2006). Platelet-derived serotonin mediates liver regeneration. Science 312, 104-107.

Martin, C.K., Redman, L.M., Zhang, J., Sanchez, M., Anderson, C.M., Smith, S.R., and Ravussin, E. (2010). Lorcaserin, a 5$\mathrm{HT}(2 \mathrm{C})$ receptor agonist, reduces body weight by decreasing energy intake without influencing energy expenditure. J. Clin. Endocrinol. Metab. 96, 837-845

Matsuda, M., Imaoka, T., Vomachka, A.J., Gudelsky, G.A., Hou, Z., Mistry, M., Bailey, J.P., Nieport, K.M., Walther, D.J., Bader, M., et al. (2004). Serotonin regulates mammary gland development via an autocrine-paracrine loop. Dev. Cell 6, 193-203.

Merens, W., Willem Van der Does, A.J., and Spinhoven, P. (2007). The effects of serotonin manipulations on emotional information processing and mood. J. Affect. Disord. 103, 43-62.

Monti, J.M. (2011). Serotonin control of sleep-wake behavior. Sleep Med. Rev. 15, 269-281.

Moore, M.C., DiCostanzo, C.A., Dardevet, D., Lautz, M., Farmer, B. Neal, D.W., and Cherrington, A.D. (2004). Portal infusion of a selective serotonin reuptake inhibitor enhances hepatic glucose disposal in conscious dogs. Am. J. Physiol. Endocrinol. Metab. 287, E1057-1063.

Murphy, D.L., and Lesch, K.P. (2008). Targeting the murine serotonin transporter: insights into human neurobiology. Nat. Rev. Neurosci. 9, 85-96.

Nomura, S., Shouzu, A., Omoto, S., Nishikawa, M., and Iwasaka, T. (2005). 5-HT2A receptor antagonist increases circulating adiponectin in patients with type 2 diabetes. Blood Coagul. Fibrinolysis 16, 423-428.

Nonogaki, K., Strack, A.M., Dallman, M.F., and Tecott, L.H. (1998). Leptin-independent hyperphagia and type 2 diabetes in mice 
with a mutated serotonin 5-HT2C receptor gene. Nat. Med. 4, $1152-1156$.

Oh, C.M., Namkung, J., Go, Y., Shong, K.E., Kim, K., Kim, H., Park, B.Y., Lee, H.W., Jeon, Y.H., Song, J., et al. (2015). Regulation of systemic energy homeostasis by serotonin in adipose tissues. Nat. Commun. 6, 6794.

Ohara-Imaizumi, M., Kim, H., Yoshida, M., Fujiwara, T., Aoyagi, K., Toyofuku, Y., Nakamichi, Y., Nishiwaki, C., Okamura, T., and Uchida, T. (2013). Serotonin regulates glucose-stimulated insulin secretion from pancreatic $\beta$ cells during pregnancy. Proc. Natl. Acad. Sci. USA 110, 19420-19425.

Rothwell, N.J., and Stock, M.J. (1987). Effect of diet and fenfluramine on thermogenesis in the rat: possible involvement of serotonergic mechanisms. Int. J. Obes. 11, 319-324.

Sakaguchi, T., and Bray, G.A. (1989). Effect of norepinephrine, serotonin and tryptophan on the firing rate of sympathetic nerves. Brain Res. 492, 271-280.

Savelieva, K.V., Zhao, S., Pogorelov, V.M., Rajan, I., Yang, Q., Cullinan, E., and Lanthorn, T.H. (2008). Genetic disruption of both tryptophan hydroxylase genes dramatically reduces serotonin and affects behavior in models sensitive to antidepressants. PLoS One 3, e3301.

Serretti, A., and Mandelli, L. (2010). Antidepressants and body weight: a comprehensive review and meta-analysis. J. Clin. Psychiatry 71, 1259-1272.

Sohn, J.W., Elmquist, J.K., and Williams, K.W. (2013). Neuronal circuits that regulate feeding behavior and metabolism. Trends Neurosci. 36, 504-512.

Sumara, G., Sumara, O., Kim, Jason K., and Karsenty, G. (2012). Gut-derived serotonin is a multifunctional determinant to fasting adaptation. Cell Metab. 16, 588-600.

Tecott, L.H., Sun, L.M., Akana, S.F., Strack, A.M., Lowenstein, D.H., Dallman, M.F., and Julius, D. (1995). Eating disorder and epilepsy in mice lacking 5-HT2c serotonin receptors. Nature 374, 542-546.

Uchida-Kitajima, S., Yamauchi, T., Takashina, Y., Okada-Iwabu, M., Iwabu, M., Ueki, K., and Kadowaki, T. (2008). 5-Hydroxytryptamine
$2 \mathrm{~A}$ receptor signaling cascade modulates adiponectin and plasminogen activator inhibitor 1 expression in adipose tissue. FEBS Lett. 582, 3037-3044.

Vickers, S.P., Clifton, P.G., Dourish, C.T., and Tecott, L.H. (1999) Reduced satiating effect of d-fenfluramine in serotonin 5-HT2C receptor mutant mice. Psychopharmacology 143, 309-314.

Wade, P.R., Chen, J., Jaffe, B., Kassem, I.S., Blakely, R.D., and Gershon, M.D. (1996). Localization and function of a 5-HT transporter in crypt epithelia of the gastrointestinal tract. J. Neurosci. 16, 2352-2364.

Walther, D.J., and Bader, M. (2003). A unique central tryptophan hydroxylase isoform. Biochem. Pharmacol. 66, 1673-1680.

Watanabe, H., Akasaka, D., Ogasawara, H., Sato, K., Miyake, M. Saito, K., Takahashi, Y., Kanaya, T., Takakura, I., Hondo, T., et al. (2010). Peripheral serotonin enhances lipid metabolism by accelerating bile acid turnover. Endocrinology 151, 4776-4786.

Yadav, V.K., Ryu, J.H., Suda, N., Tanaka, K.F., Gingrich, J.A. Schutz, G., Glorieux, F.H., Chiang, C.Y., Zajac, J.D., Insogna, K.L., et al. (2008). Lrp5 controls bone formation by inhibiting serotonin synthesis in the duodenum. Cell 135, 825-837.

Yamakawa, J., Takahashi, T., Itoh, T., Kusaka, K., Kawaura, K., Wang, X.Q., and Kanda, T. (2003). A novel serotonin blocker, sarpogrelate, increases circulating adiponectin levels in diabetic patients with arteriosclerosis obliterans. Diabetes Care 26, 24772478.

Young, S.N., and Leyton, M. (2002). The role of serotonin in human mood and social interaction: Insight from altered tryptophan levels. Pharmacol. Biochem. Behav. 71, 857-865.

Zhang, X., Beaulieu, J.M., Sotnikova, T.D., Gainetdinov, R.R., and Caron, M.G. (2004). Tryptophan hydroxylase-2 controls brain serotonin synthesis. Science 305, 217

Zhou, L., Sutton, G.M., Rochford, J.J., Semple, R.K., Lam, D.D., Oksanen, Laura J., Thornton-Jones, Z.D., Clifton, P.G., Yueh, C.Y., Evans, M.L., et al. (2007). Serotonin 2C receptor agonists improve type 2 diabetes via melanocortin-4 receptor signaling pathways. Cell Metab. 6, 398-405. 